\title{
Cervical length by ultrasound as a predictor of preterm labour
}

\author{
Jasmina Begum $^{1}$, Ashok Kumar Behera ${ }^{2}$
}

\author{
${ }^{1}$ Department of Obstetrics \& Gynecology, MGMC \& RI, Pillaiyarkuppam-607402, Puducherry, India \\ ${ }^{2}$ Department of Obstetrics \& Gynecology, MKCG Medical College, Berhampur-760004, Odisha, India
}

Received: 9 July 2014

Accepted: 20 July 2014

\author{
*Correspondence: \\ Dr. Jasmina Begum, \\ E-mail: jasminaaly@gmail.com
}

(C) 2014 Begum J et al. This is an open-access article distributed under the terms of the Creative Commons Attribution Non-Commercial License, which permits unrestricted non-commercial use, distribution, and reproduction in any medium, provided the original work is properly cited.

\begin{abstract}
Background: Objective of current study was to evaluate cervical length by transabdominal and transvaginal ultrasonography at 14-24 weeks of gestation in asymptomatic women for predicting women at risk of preterm delivery and to find out the one method which is more accurate of the two.

Methods: Fifty one women were enrolled in this prospective study. Women with cervical incompetence, multiple gestation, maternal medical diseases, previous cervical surgery were excluded. Each woman underwent a transabdominal and transvaginal ultrasonographic cervical length measurement. The period of gestation at delivery in these women was then correlated with sonographic findings. Statistical comparisons were made between the two ultrasonographic methods.

Results: Preterm delivery occurred in $37.2 \%$ of the women. By transabdominal sonography it was seen that with cervical length of less than $3 \mathrm{~cm}$ at $14-24$ weeks, majority $(63.15 \%)$ delivered preterm. The mean cervical length of cases who delivered preterm was $3.3 \pm 0.9 \mathrm{~cm}$. Whereas the mean cervical length of cases that had term delivery was $3.5 \pm 0.6$, and majority $(86.2 \%)$ had cervical length of more than $3 \mathrm{~cm}$, similar trend was also seen with transvaginal sonography, majority $(78.9 \%)$ of cases with cervical length of less than $3 \mathrm{~cm}$ delivered preterm. The mean cervical length of cases who delivered at term was $3.1 \pm 0.4$ and the mean cervical length of cases who delivered preterm was $2.85 \pm 0.5 \mathrm{~cm}$. There was definitive positive correlation between cervical length at 14-24 weeks and period of gestation at delivery. On analysis, prediction of risk of preterm delivery by cervical length cut off value on the basis of the median at earlier weeks, $35 \mathrm{~mm}$ for transabdominal and $30 \mathrm{~mm}$ for transvaginal sonography, it was observed that transabdominal sonography with a sensitivity of $63.15 \%$ and specificity of $71.8 \%$, predicted relative risk of 2.47 which was not significant $(\mathrm{P}<0.1)$ but transvaginal sonography with sensitivity of $78.9 \%$ and specificity of 81.2 predicted relative risk of 5.35 which was significant $(\mathrm{P}<0.001)$.

Conclusions: Transvaginal ultrasonography seems to be the optimal method for assessment of cervical length in the second trimester and for screening for spontaneous preterm delivery.
\end{abstract}

Keywords: Preterm delivery, Cervical length, Transabdominal sonography (TAS), Transvaginal sonography (TVS)

\section{INTRODUCTION}

Preterm birth is the leading cause of perinatal mortality and morbidity. Inspite of advances in perinatal care the incidence of preterm delivery, with its attendant perinatal morbidity \& mortality, has remained at a discouragingly unaltered rate of $10 \%$ at all births. ${ }^{1}$ It is responsible for $85 \%$ of neonatal death in normally formed infants and even for those who survive, the sequelae of an untimely birth often result in permanent disabilities. ${ }^{2}$ The agony of life-long suffering because of neonatal or physical impairment is surely one of the greatest tragedies that can beset a person, his or her family, society and even the economies of the world. Preterm birth accounts for $70 \%$ of neonatal morbidity, mortality and health care cost to society for neonates. ${ }^{3}$ 
Due to poor success rates in inhibiting labour once it has started, over the years attention has shifted in identification of patients at risk for preterm delivery and aggressive preventive programmes. Numerous pregnancy related complications increases the risk of preterm birth, which the maternal risk scoring fails to detect. ${ }^{4}$ The clinical digital examination of cervix and biochemical tests have very low sensitivity and specificity making them useless in clinical practice. ${ }^{5-7}$

During the last two decades, the detection of fetal fibronectin from cervicovaginal secretions and cervical changes diagnosed by transvaginal sonography have emerged as a major predictor of preterm birth. ${ }^{8}$ With the experience now accrued, it is universally agreed that the shorter the cervical length, the greater is the risk of spontaneous preterm labour. With the availability of high resolution, non-invasive obstetric sonography, alteration of cervical anatomy may be measured accurately with the objectivity, safety and replicability that clinical digital examination cannot provide. Indeed ample evidence in the literature supports the reliability of sonographic evaluation of cervical shortening as measured by cervical length in assessment of preterm cervix. ${ }^{9}$

These previous studies confirm the sensitivity of sonography in cervical length measurement and the strong association between premature cervical length shortening and clinical preterm labour in high risk population. However, these large series fail to provide sonographic evaluation of cervical length for normal term pregnancy, or to evaluate cervical length alteration in asymptomatic group.

Hence the present study was proposed to delineate the cervical changes in cases that will end up in preterm delivery from cervical changes that ends in term delivery. So that this cervical changes can be applied to the active antepartum management of women suspected to be at risk of preterm delivery.

\section{METHODS}

This was a prospective study done in the department of obstetrics and gynecology, MKCG medical college and hospital Berhampur, Odisha after getting approval from ethical committee.

\section{Selection of cases}

Out of the obstetric cases attending the antenatal OPD of the dept. of obstetrics \& gynecology, cases of singleton pregnancies were selected at random after thorough history taking and meticulous clinical examination.

Prior to commencement of first examination, informed consent was taken and the patient was explained about the study. The cases were recruited after selection, basing on following criteria.

\section{Criteria for exclusion}

All high risk cases where preterm delivery is contemplated as a part of the obstetric management (multiple gestation, PIH, IUGR, Diabetes, previous unexplained intrauterine death, congenital uterine anomalies, polyhydraminos, antepartum haemorrage).

$>$ Cases lost to follow up.

$>$ Cases in which cervical assessment by ultrasound was not satisfactory or inconclusive.

\section{Criteria for inclusion}

$>$ Primigravida with singleton pregnancy without any high risk factors requiring preterm delivery

$>$ Multigravida with normal obstetric history.

$>$ Multigravida with history of abortion (early and late) and preterm birth.

Pregnant women between 14 to 24 weeks were selected. History taking and clinical examination was done in these patients. Special emphasis was given to obstetrics history. Cases satisfying selection criteria were recruited. They were subjected to transabdominal ultrasonography and transvaginal sonography for evaluation of cervical length. Sonographic evaluation of the cervix was done with a real time equipment (WIPRO-GRT 2000) using a 3.5 $\mathrm{MHz}$ transducer for abdominal sonography and 5-7.5 $\mathrm{MHz}$ transducer for transvaginal sonography.

Each woman underwent a transabdominal ultrasonographic measurement of cervical length with full bladder. Then, the subjects were asked to empty their bladder and transvaginal ultrasonographic cervical length measurement was performed in the lithotomy position with a 5-7.5 MHz transvaginal probe. The entire cervical canal was visualized both in abdominal and transvaginal routes. Markers were placed in the furthest points between the internal Os and the external Os, two measurements were obtained for each route and the minimum values were recorded. All examinations were performed by same examiner.

All women were followed throughout the course of gestation and delivered in our hospital. None underwent induced preterm delivery because of other gestational complications. Data was analyzed and statistical comparisons were made between the two ultrasonographic methods for gestational age at birth and parity. Predictive value of the mean cervical length measurement for preterm birth, sensitivity, specificity, positive and negative predictive values for mean \pm standard deviation of the mean cervical length of all subjects was calculated. $30 \mathrm{~mm}$ for transvaginal and 35 $\mathrm{mm}$ for transabdominal ultrasonography were taken as 
cut-off values. Data was analyzed using Chi square test and student $t$ test.

\section{RESULTS}

This study included 51 cases selected as per the selection criteria. 22 cases $(43.12 \%)$ were primigravida and 29 cases $(56.86 \%)$ were multigravida.

Table 1, shows there were 23 cases with risk factors for preterm labour out of which, 5 cases $(21.73 \%)$ had history of early abortion, 4 cases $(17.3 \%)$ had history of late abortion and 14 cases $(60.8 \%)$ had history of preterm labour.
Table 1: Distribution of cases with risk factors of preterm delivery.

\begin{tabular}{|lll|}
\hline Risk factor & No. of cases & Percentage \\
\hline H/o early abortion & 5 & 21.73 \\
\hline H/o late abortion & 4 & 17.3 \\
\hline H/o preterm labour & 14 & 60.8 \\
\hline Total & 23 & 100 \\
\hline
\end{tabular}

Table 2, shows out of total number of 51 cases, 22 cases were primigravida from which 15 cases $(68.18 \%)$ had term delivery and 7 cases $(31.81 \%)$ had preterm delivery. Out of 29 cases of multigravida 17 cases $(58.36 \%)$ had term delivery and 12 cases $(41.37 \%)$ had preterm delivery.

Table 2: Distribution of cases according to gestational age at delivery.

\begin{tabular}{|lllllll|}
\hline \multirow{2}{*}{$\begin{array}{l}\text { Period of } \\
\text { gestation }\end{array}$} & $\begin{array}{l}\text { Gravida } \\
\text { Primi }\end{array}$ & No. of cases & \% & Multi & $\begin{array}{l}\text { Total no. } \\
\text { of cases }\end{array}$ & Percentage \\
\cline { 2 - 6 } & 15 & 68.18 & 17 & 58.36 & 32 & 62.7 \\
\hline Term & 7 & 31.81 & 12 & 41.37 & 19 & 37.25 \\
\hline Treterm & 22 & 100 & 29 & 100 & 51 & 100 \\
\hline
\end{tabular}

Cervical length by different method has been compared between cases who delivered preterm and term in Table 3 . There were 32 cases who delivered at term. The mean cervical length by TAS at 14-24 weeks was $3.5 \pm 0.6 \mathrm{~cm}$ and by TVS was $3.1 \pm 0.41 \mathrm{~cm}$. There were 19 cases that had preterm delivery and their cervical length by TAS was $3.3 \pm 0.94$ and by TVS was $2.8 \pm 0.5 \mathrm{~cm}$ at $14-24$ weeks.

Table 3: Comparison of cervical length measurements (in $\mathrm{cm}$ ) between patients who delivered preterm and term.

\begin{tabular}{|lllll|}
$\begin{array}{l}\text { Type of } \\
\text { examination }\end{array}$ & $\begin{array}{l}\text { Weeks of } \\
\text { gestation }\end{array}$ & $\begin{array}{l}\text { Term delivery } \\
(\mathbf{n}=\mathbf{3 2})\end{array}$ & $\begin{array}{l}\text { Preterm delivery } \\
(\mathbf{n}=\mathbf{1 9})\end{array}$ & P value \\
\hline TAS & $14-24$ weeks & $3.5 \pm 0.6$ & $3.3 \pm 0.94$ & $<0.1$ \\
\hline TVS & $14-24$ weeks & $3.1 \pm 0.41$ & $2.85 \pm 0.5$ & 0.001 \\
\hline
\end{tabular}

Table 4: Risk of preterm delivery by cervical length cut off value of $35 \mathrm{~mm}$ for TAS and $30 \mathrm{~mm}$ for TVS.

\begin{tabular}{|c|c|c|c|c|c|c|c|c|c|}
\hline $\begin{array}{l}\text { Type of } \\
\text { examination }\end{array}$ & $\begin{array}{l}\text { Cut off } \\
\text { length } \\
(\mathrm{mm})\end{array}$ & $\begin{array}{l}>\text { Cut off } \\
\text { Risk of } \\
\text { PTL (\%) }\end{array}$ & $\begin{array}{l}\text { Risk of } \\
\text { PTL (\%) }\end{array}$ & Sensitivity & Specificity & $\begin{array}{l}\text { Positive } \\
\text { predictive } \\
\text { value }\end{array}$ & $\begin{array}{l}\text { Negative } \\
\text { predictive } \\
\text { value }\end{array}$ & $\mathbf{R R}$ & P value \\
\hline TAS & $35 \mathrm{~mm}$ & 13.7 & 23.5 & 63.15 & 71.8 & 57.1 & 76.6 & 2.4 & $<0.1$ \\
\hline TVS & $30 \mathrm{~mm}$ & 7.89 & 29.4 & 78.9 & 81.2 & 71.4 & 86.6 & 5.3 & 0.001 \\
\hline
\end{tabular}

Table 4, shows the predictive value of cervical length for risk of preterm delivery. By TAS with cut off value for cervical length of $35 \mathrm{~mm}$ and when the value was more than the cut off, the risk of preterm delivery was $13.7 \%$ but when the cervical length was less than equal to cut off, the risk of preterm delivery was $23.5 \%$ with a sensitivity of $63.15 \%$, specificity of $71.8 \%$, positive predictive value of $57.1 \%$, negative predictive value of $76.6 \%$ and relative risk of 2.47 . By TVS with cut off value for the cervical length of $30 \mathrm{~mm}$, when the value 
was more than the cut off the risk of preterm delivery was $7.89 \%$ but when the cervical length was less than equal to cut off the risk preterm delivery was $29.4 \%$ and relative risk of 5.35 , with a sensitivity of $78.9 \%$ and specificity of $81.2 \%$, positive predictive value of $71.4 \%$, negative predictive value of $86.6 \%$.

In Table 5, there were 7 cases of primigravida who delivered preterm; they had a mean cervical length of 3.6 $\pm 0.53 \mathrm{~cm}$ with a range of $3-4 \mathrm{~cm}$, by TAS and the mean cervical length of $3.07 \pm 0.7 \mathrm{~cm}$ with a range of $2-4 \mathrm{~cm}$, by TVS (P 0.77). There were 12 cases of multigravida with history of early or late abortion or preterm labour who delivered preterm, they have a mean cervical length of $3.7 \pm 0.82 \mathrm{~cm}$ with a range of $2-5 \mathrm{~cm}$, by TAS and the mean cervical length of $2.47 \pm 0.53$ with a range of $2-3$ cm by TVS $(\mathrm{P}<0.04)$.

Table 5: Comparison between cervical changes in multigravida with risk of abortion \& preterm labour and primigravida by TAS, and TVS who had delivered preterm (14-24 weeks).

\begin{tabular}{|c|c|c|c|c|c|}
\hline \multirow{3}{*}{ Group } & \multirow{3}{*}{ No. of cases } & \multirow{2}{*}{\multicolumn{2}{|c|}{$\begin{array}{l}\text { TAS } \\
\text { Length in } \mathbf{c m}\end{array}$}} & \multirow{2}{*}{\multicolumn{2}{|c|}{$\begin{array}{l}\text { TVS } \\
\text { Length in cm }\end{array}$}} \\
\hline & & & & & \\
\hline & & Range & Mean \pm SD & Range & Mean \pm SD \\
\hline Multi with risk & 12 & $2-5$ & $3.7 \pm 0.82$ & $2-3$ & $2.47 \pm 0.53$ \\
\hline Primigravida & 7 & $3-4$ & $3.6 \pm 0.53$ & $2-4$ & $3.07 \pm 0.7$ \\
\hline$P$ value & & & 0.77 & & 0.04 \\
\hline
\end{tabular}

Table 6 , the relative risk of preterm delivery in short cervix $(<3.5 \mathrm{~cm})$ by TAS is 3.6 in primigravida and $1.3 \mathrm{in}$ case of multigravida with history of abortion and preterm labour and by TVS it is 0.73 in primigravida and 1.3 in multigravida, with history of abortion and preterm labour.

Table 6: Relative risk of preterm delivery in primigravida and multigravida with history of abortion and preterm labour by TAS (cut of $<3.5 \mathrm{~cm}$ ), TVS $(<3.0 \mathrm{~cm})$.

\begin{tabular}{|lll|} 
Method & Primigravida & $\begin{array}{l}\text { Multigravida } \\
\text { with H/o of } \\
\text { abortions and } \\
\text { preterm labour }\end{array}$ \\
\cline { 2 - 3 } TAS & Cervical length & Cervical length \\
\hline TVS & 3.6 & 1.3 \\
\hline
\end{tabular}

\section{DISCUSSION}

In developing countries, the major cause of perinatal morbidity and mortality is preterm birth. Predicting spontaneous preterm birth will help in early intervention and improvement in outcome. Numerous investigators have developed risk scoring systems but there is still no reduction in the rate of preterm birth in the general population. $^{10} \mathrm{~A}$ short cervix at ultrasonography was reported as an independent predictor of preterm delivery. $^{11,12}$

For preterm delivery risk assessment, cervical evaluation by ultrasonography is neither routine nor any standardization has been established. With this background the present study was undertaken. All high risk cases like PIH, IUGR, diabetes, previous unexplained intrauterine death, $\mathrm{Rh}$ negative women, cases of multifetal gestations and confirmed cervical incompetence were excluded. These confounding factors were excluded.

The cases on enrollment were subjected to transabdominal and transvaginal sonography for evaluation of cervical length at 14-24 weeks. The examination was done only once with the objective to find out usefulness of at least one examination to detect cases at risk of preterm labour. This study of one examination, have also been supported by other studies like Anderson et al. (1990), Berghella et al. (1997) and Heath et al. (1998). ${ }^{13-15}$ Majority of patients in the present study $56.87 \%$ were multigravida and the rest $43.13 \%$ were primigravida. In this study over all $37.25 \%(19 / 51)$ had preterm delivery. Among the primigravida there were $31.81 \%$ preterm births and among the cases of multigravida there was $41.37 \%$ preterm birth (Table 2). The multigravida who had no history of any abortion or preterm delivery, all delivered at term. The multigravida who had history of early or late abortion or history of preterm delivery $47.8 \%(12 / 23)$ had preterm delivery (Table 1, 5).

In the present study, the mean cervical length who delivered preterm among primigravida was $3.6 \pm 0.53$ and multigravida with history of abortion and preterm labour was $3.7 \pm 0.82$ by TAS. There was no significant difference. By TVS the mean cervical length in above 2 groups was $3.07 \pm 0.7$ in primigravida and $2.47 \pm 0.53$ in multigravida, which shows significant difference of $\mathrm{P}$ $<0.04$ (Table 5). Gamze et al. (2005) also reported similar result in primigravida with mean cervical length of $3.6 \pm$ 8.4 by TAS and $4.5 \pm 7.6$ by TVS and multigravida women of $3.3 \pm 6.7$ by TAS and $4.1 \pm 7.2$ by TVS. TVS measurement showed a statistically significant difference 
between primigravida and multigravida women ( $\mathrm{P}$ $<0.05)$, the difference was at significant limit by TAS (P $=0.05){ }^{16}$

In the present study (Table 6) the Relative Risk (RR) of preterm delivery in primigravida was 3.6 by TAS and 0.73 by TVS and multigravida with history of abortion and preterm labour it was 1.3 by TAS and 1.3 by TVS from observations. Considering cervical length by TAS (cutoff $\leq 3.5 \mathrm{~cm}$ ) the RR of primigravida is more than multigravida where as in case by TVS (cut off $\leq 3.0 \mathrm{~cm}$ ) $\mathrm{RR}$ of multigravida was more than primigravida.

This was supported by the study conducted by Hasegawa et al. (1996), the group with shortened cervix showed a significantly high preterm delivery rate (OR: 4.86). ${ }^{11}$

\section{Cervical length and preterm birth}

By transabdominal sonography it was seen that with cervical length of less than $3 \mathrm{~cm}$ at 14-24 weeks, majority $(63.15 \%)$ delivered preterm. The mean cervical length of cases who delivered preterm was $3.3 \pm 0.9 \mathrm{~cm}$ whereas the mean cervical length of cases that had term delivery was $3.5 \pm 0.6$, and majority $(86.2 \%)$ had cervical length of more than $3 \mathrm{~cm}$. Similar trend was also seen with transvaginal sonography, majority $(78.9 \%)$ of cases with cervical length of less than $3 \mathrm{~cm}$ delivered preterm. The mean cervical length of cases who delivered at term was $3.1 \pm 0.4$ and the mean cervical length of cases who delivered preterm was $2.85 \pm 0.5 \mathrm{~cm}$.

Several studies have demonstrated an inverse relationship between the length of cervix as measured by ultrasonography during pregnancy and spontaneous preterm delivery. The shorter the cervix, the greater the likelihood of preterm delivery Anderson et al. (1990), Iams et al. (1996) observed that in patients with cervical length of more than $3 \mathrm{~cm}$ at $20-24$ weeks $93.4 \%$ delivered at term and with a cervical length of less than $3 \mathrm{~cm}$, $100 \%$ delivered preterm, which in similar to our study. $^{13,17}$

\section{Comparative analysis of cervical parameters by different methods for prediction of preterm birth}

Table 3 shows that the cervical length varied from $2-5 \mathrm{~cm}$ by TAS but from 2-4 cm by TVS at 14-24 weeks. The mean cervical length observed by TVS at 14-24 weeks $(2.85 \pm 0.5 \mathrm{~cm})$ was less than that observed by TAS $(3.3$ $\pm 0.94 \mathrm{~cm}$ ) in cases who delivered preterm.

For cases who had term deliveries, the mean cervical

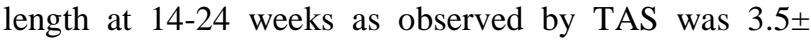
$0.6 \mathrm{~cm}$ against $3.1 \pm 0.41 \mathrm{~cm}$ by TVS. There was little difference in the cervical length by two methods.

Analyzing the data depicted in Table 3, it is observed that the mean cervical length was 3-5 mm more when examined by TAS than by TVS for both cases that had term and preterm delivery, irrespective of gestational period. The difference between the mean cervical length between the cases of preterm and term deliveries was statistically significant ( $\mathrm{P}<0.1$ to $<0.001$ ). Among the 2 types of examination done, considering the cervical length, it was found that TVS has higher probability of predicting the outcome of preterm labour. It was statistically significant $(\mathrm{P}<0.001)$.

The mean cervical length at different gestation had been reported by different authors. Pietrygam et al. had investigated 119 pregnant women by TVS between 23 and 29 weeks gestation. They found mean cervical length was $1.6 \pm 0.5 \mathrm{~mm}$ in pregnancies delivered before term $(\mathrm{n}=19)$ and $3.0 \pm 0.6 \mathrm{~mm}$ in pregnancies delivered at term $(n=100)$. This difference from present study could be attributed to smaller sample size, and evaluation done between 14-24 weeks. However, individual variation in assessment also cannot be ruled out. ${ }^{18}$

Gamze et al., had evaluated 120 pregnant women between 20-24 weeks. The mean cervical length was found to be $3.5+0.7 \mathrm{~mm}$ by TAS and $4.3 \pm 0.7 \mathrm{~mm}$ by TVS. They had taken $3.6 \mathrm{~cm}$ for TVS and $2.7 \mathrm{~cm}$ for TAS as cut off values. They showed that the TVS measurement of cervical length in second trimester is an optimal method for cervical assessment for spontaneous preterm delivery with significant statistical difference between term and preterm delivery. No significant difference was found in TAS. ${ }^{16}$

\section{Parameters of predictive value of different methods of assessment of cervical conditions}

The cut off values for cervical length at 14-24 weeks was taken to be $\leq 3.5 \mathrm{~cm}$ respectively for transabdominal examination. Similarly, for transvaginal sonography the cut off values for cervix length was $\leq 3 \mathrm{~cm}$ respectively.

The sensitivity, specificity, PPV and NPV for cervical length by TAS at $14-24$ weeks were $63.15 \%, 71.8 \%$, $57.1 \%, 76.6 \%$ (Table 4). Considering cervical length by TAS, though the specificity of the TAS is high, predicting the outcome of the preterm labour is high, but its sensitivity and positive predictive is low. Hence this is not a satisfactory test.

The predictive parameters, sensitivity, specificity, PPV and NPV by TVS for cervical length at 14-24 weeks were $78.9 \%, 81.2 \%, 71.4 \%, 86.6 \%$ respectively (Table 5). Considering cervical length by TVS, both the sensitivity, specificity, PPV at 14-24 weeks were high. Hence this mode of screening test is ideal for predicting the outcome of preterm labour.

In the study on prediction of preterm labour by TAS, Tongsong et al. reported sensitivity $65.9 \%$, specificity $62.4 \%$ at cut off of $<35 \mathrm{~mm}$, for cervical length which is similar to the present study. ${ }^{19}$

Iams et al., stated that the cervical ultrasonography in patients with low risk, asymptomatic patients seems to be 
most predictive of preterm delivery. By doing TVS they showed a sensitivity of $54 \%$, specificity of $76.3 \%$, PPV of $9.3 \%$, NPV of $97.4 \%$ at 24 weeks with cut off $<30$ mm. ${ }^{17}$ Our results are nearly similar. The study on prediction of preterm labour by TVS at cut off $<34 \mathrm{~mm}$ upto 30 weeks gestational age in asymptomatic patient by Anderson et al reported specificity $84 \%$, NPV of $89.9 \%$, sensitivity of $47 \%$ and PPV of $34.8 \% .^{13}$

In the present study by TVS at cut off of $<30 \mathrm{~mm}$ in asymptomatic patient between 14-24 weeks have similar specificity and NPV, but there is no increase in sensitivity and PPV in comparison to above the study, this may be due to cut off value .

\section{Risk of preterm delivery}

On analysis, prediction of risk of preterm delivery by cervical length cut off value on the basis of the median at earlier weeks, $35 \mathrm{~mm}$ for TAS and $30 \mathrm{~mm}$ for TVS, (Table 4), it was observed that TAS with a sensitivity of $63.15 \%$ and specificity of $71.8 \%$ predicted relative risk of 2.47 which was not significant $(\mathrm{P}<0.1)$ but TVS with sensitivity of $78.9 \%$ and specificity of $81.2 \%$ predicted relative risk of 5.35 which was significant $(\mathrm{P}<0.001)$.

Considering cervical length by TVS the risk of preterm delivery is highest $29.4 \%$ when the cut off value is $30 \mathrm{~mm}$, and the risk is 5 times when the length is less than $30 \mathrm{~mm}$ and this difference between prediction of preterm delivery is found to be statistically significant $(\mathrm{P}<0.001)$ (Table 4).

Following Table compares the various observations with the present study: ${ }^{13,19,17,20}$

Table 7: Comparison of the various observations with the present study.

\begin{tabular}{|llll|}
\hline Authors & $\begin{array}{l}\text { Gestation } \\
\text { age (weeks) }\end{array}$ & $\begin{array}{l}\text { Cervical } \\
\text { length cut } \\
\text { off by TVS } \\
\text { (mm) }\end{array}$ & RR \\
\hline Anderson et al. & $12-30$ & 39 & 3.75 \\
\hline Tongsong et al. & $28-30$ & 35 & 2.77 \\
\hline Iams et al. & 24 & 26 & 6.19 \\
\hline Honest et al. & 28 & 26 & 9.57 \\
\hline Present study. & $14-24$ & 30 & 6.29 \\
\hline
\end{tabular}

Several studies have demonstrated an inverse relationship between the length of the cervix, as measured by ultrasonography during pregnancy and the frequency of spontaneous preterm delivery. The shorter the cervix, the greater is the likelihood of preterm delivery. However, different cut off points of cervical length and different definitions of preterm birth ( $<35$ weeks versus $<37$ weeks) were used by different investigators and the study population were different (low risk versus high risk).

\section{CONCLUSION}

The study was not designed to compare management protocols for prevention of preterm labour. Instead, our results demonstrate that sonographic evaluation of cervical length is a reliable non-invasive method of objectively assessing the changes in cervical anatomy that may be associated with an increased risk of preterm delivery. Of all, shortening of cervical length had the maximum predictive value. Cervical changes in earlier weeks of pregnancy are more indicative of cases at risk of developing preterm labour. TVS evaluation of cervix is more accurate than TAS. According to the present study a cut off value of $30 \mathrm{~mm}$ between 14-24 weeks is highly predictive of relative risk of preterm delivery. Even though our demerit was a small sample size still we could come to the common established outcome.

Funding: No funding sources

Conflict of interest: None declared

Ethical approval: The study was approved by the institutional ethics committee

\section{REFERENCES}

1. Berkowith GS, Papiernick E. Epidemiology of preterm birth. Epidemiol Rev. 1993;15:414-43.

2. Copper RL, Goldenberg RL, Davis RO, Cutter GR, DuBard MB, Corliss DK, et al. Warning symptoms, uterine contractions and cervical examination findings in women at risk of preterm delivery. Am J Obstet Gynecol. 1990 Mar;162(3):748-54.

3. Steer P. The epidemiology of preterm labour: why have advances not equated to reduced incidences? $\mathrm{Br}$ J Ostet Gynecol. 2006;113:1-3.

4. Armson BA, Dodds L. Prediction of preterm birth in a population of Canadian women. Int $\mathrm{J}$ Gynecol Obset. 1994;46(Suppl 2):93.

5. Gomez R, Glasso M, Romero R, Mazor M, Sorokin $\mathrm{Y}$, Gonçalves L, et al. Ultrasonographic examination of uterine cervix is better than cervical digital examination as the predictor of likelihood premature delivery in patients with preterm labour and intact membrane. Am J Obstet Gynecol. 1994;171:956-64.

6. Vogel I, Grove J, Thorsen P, Moestrup SK, Uldbjerg N, Møller HJ. Preterm delivery predicted by soluble CD 163 and CRP in women with symptoms of preterm delivery. $\mathrm{Br} \mathrm{J}$ Obstet Gynecol. 2005;112:737-42.

7. Goldenberg RL, Hauth JC, Andrew WW. Intrauterine infection and preterm delivery. $\mathrm{N}$ Eng $\mathrm{J}$ Med. 2000 May; 18:342.

8. Leitch H. Secondary predictors of preterm labour. $\mathrm{Br}$ J Ostet Gynecol. 2005 Mar;112:48-50.

9. Brown JE, Thieme GA, Shah DM, Fleischer AC, Boehm FH. Transabdominal and transvaginal endosonography: evaluation of the cervix and lower uterine segment in pregnancy. Am J Obstet Gynecol. 1986;155:721-6. 
10. Goldenberg RL, Lams JD, Mercer BM, Meis PJ, Mowad A, Cooper RL, et al. The preterm prediction study: the value of new vs. standard risk factors in predicting all early and spontaneous preterm births NICHD MFMU Network. Am J Publ Health. 1998;88:233-8.

11. Hasegawa I, Tanaka K, Tanaka T, Aoki K, Okai T, Takahashi K. A Prospective clinical study for the prediction of preterm delivery in a low risk population. J Mat Fetal Med. 1996 Nov;6:148-51.

12. Boties D, Papagianni V, Vitoratos V, Makrakis E, Aravantinos L, Creatsas G. Prediction of preterm delivery by sonographic estimation of cervical length. Biol Neonate. 2005;88(1):42-5.

13. Anderson HF, Nugent CE, Wanty SB, Hayashi RH. Prediction of risk for preterm delivery by ultrasonographic measurement of cervical length. Am J Obstet Gynecol. 1990;163:859-67.

14. Berghella V, Talcci M, Desai A. Does transvaginal sonographic measurement of cervical length before 14 weeks predict preterm delivery in high risk pregnancies? Ultrasound Obstet Gynecol. 2003 Feb;21:140-4.

15. Heath VC, Souka AP, Southhall TR, Nicolaides KH. Cervical length at 28 weeks of gestation, prediction of spontaneous preterm delivery. Ultrasound Obstet Gynecol. 1998;12;312-7.

16. Gamze C, Cidgem S, Senol K, Filiz A. Evaluation of length of cervix by transvaginal and transabdominal ultrasonography in second trimester. J Obstet Gynecol India. 2005;55:318-21.

17. Iams JD, Goldenberg RL, Meis PJ. The length of cervix and risk of spontaneous PTD. N Eng J Med. 1996;334:567.

18. Pietryaga M, Brazert J, Wender-Ozegowska E, Mitkowska H, Persona-Sliwińska A, Biczysko R. Cervical ultrasound assessment for predicting the risk of premature delivery. Med Wieku Rozwoj. 2003 Jul-Sep;7(3 Suppl 1):157-65.

19. Tongsong T, Kamprapanth P, Pitaksakorn J. Cervical length in normal pregnancy as measured by transvaginal sonography. Int $\mathbf{J}$ Gynecol Obstet. 1995;58:313-5.

20. Honest H, Bachmann LM, Coomaraswamy A, Gupta JK, Kleijnen J, Khan KS. Accuracy of cervical transvaginal sonography in predicting preterm birth. Ultrasound Obstet Gynecol. 2003;22:305-22.

DOI: $10.5455 / 2320-1770 . i j r \operatorname{cog} 20140950$

Cite this article as: Begum J, Behera AK. Cervical length by ultrasound as a predictor of preterm labour. Int J Reprod Contracept Obstet Gynecol 2014;3:646-52. 